\title{
The role of multimodality imaging in HIV-related heart disease
}

\author{
Sudeep Raj Aryal, MD, ${ }^{\text {a }}$ Navkaranbir S. Bajaj, MD, MPH, ${ }^{a}$ Gregory Von Mering, \\ $M D,{ }^{\mathrm{a}, \mathrm{b}}$ and Mustafa I. Ahmed, $\mathrm{MD}^{\mathrm{a}, \mathrm{b}}$ \\ a Division of Cardiovascular Disease, The University of Alabama at Birmingham, Birmingham, AL \\ b UAB Structural Heart \& Valve Clinic at Spain Wallace, Birmingham, AL
}

Received Jun 29, 2020; accepted Jun 29, 2020

doi: $10.1007 / \mathrm{s} 12350-020-02291-1$

See related article, pp. 510-530

\section{INTRODUCTION}

The review by Mondal et al. in this issue of the Journal of Nuclear Cardiology ${ }^{1}$ describes the mechanisms, management, and role of imaging in coronary artery disease (CAD) associated with human immunodeficiency virus (HIV). Although CAD is the predominant cardiac manifestation of HIV, other cardiac manifestations are frequent and deserve appropriate attention. Our editorial builds up and elaborates on the review by Mondal et al. and briefly discusses all common cardiac manifestations of HIV and supportive imaging modalities for diagnosis and management.

Antiretroviral therapy (ART) against HIV has significantly improved life expectancy among those affected with HIV., ${ }^{2,3}$ However, this has resulted in an exponential rise in non-HIV-related morbidity especially those associated with cardiovascular disease (CVD). ${ }^{4,5}$ We summarize below the mechanisms and possible role of multimodal imaging to diagnose and follow HIVrelated cardiac manifestations.

Funding Drs. Aryal, Bajaj, VonMering and Ahmed received no funding for this manuscript

Reprint requests: Sudeep Raj Aryal, MD, Division of Cardiovascular Disease, The University of Alabama at Birmingham, Birmingham, AL; saryal@uabmc.edu

J Nucl Cardiol 2021;28:531-5.

$1071-3581 / \$ 34.00$

Copyright (c) 2020 American Society of Nuclear Cardiology.

\section{MECHANISMS OF CARDIAC MANIFESTATIONS IN HIV}

Although is the most common manifestation of HIV-related heart disease, HIV can affect heart in several ways. (Figure 1) Traditional risk factors like smoking, obesity, diabetes are more prevalent among HIV affected individuals than unaffected individuals leading to higher prevalence of CAD. ${ }^{6-8}$ Inflammation and immune dysfunction are hallmark of HIV and among the major risk factors which lead to a myriad of manifestations like myocarditis with associated cardiomyopathy, arrhythmia, coagulation disorders, pericardial disease, and arteriopathy causing pulmonary hypertension. ${ }^{9-11}$ Furthermore, behavioral and psychiatric disorders are more common in those with HIV making these patients prone to cardiovascular risk of psychiatric and illicit drugs use. ${ }^{12}$

ART despite their good efficacy against HIV are associated with significant side effects like dyslipidemia which in turn lead to CAD. ${ }^{13}$ These therapies may also have serious interactions with other therapies causing cardiac toxicity. ${ }^{14}$ The opportunistic infections associated with advanced HIV can lead to valvular heart disease and cardiac neoplasm. ${ }^{3}$ Kaposi sarcoma and malignant lymphoma are some of the common malignancies involving the heart, pericardium, coronary artery adventitia, and the great vessels. ${ }^{15}$

\section{ROLE OF IMAGING MODALITIES IN HIV- RELATED HEART DISEASE}

HIV can affect the heart in several ways as described above hence HIV-related heart disease presents a perfect target for multimodality imaging to elucidate diagnosis and mechanisms for personalized treatment of these patients. Table 1 describes how imaging modalities can elucidate the complex nature 

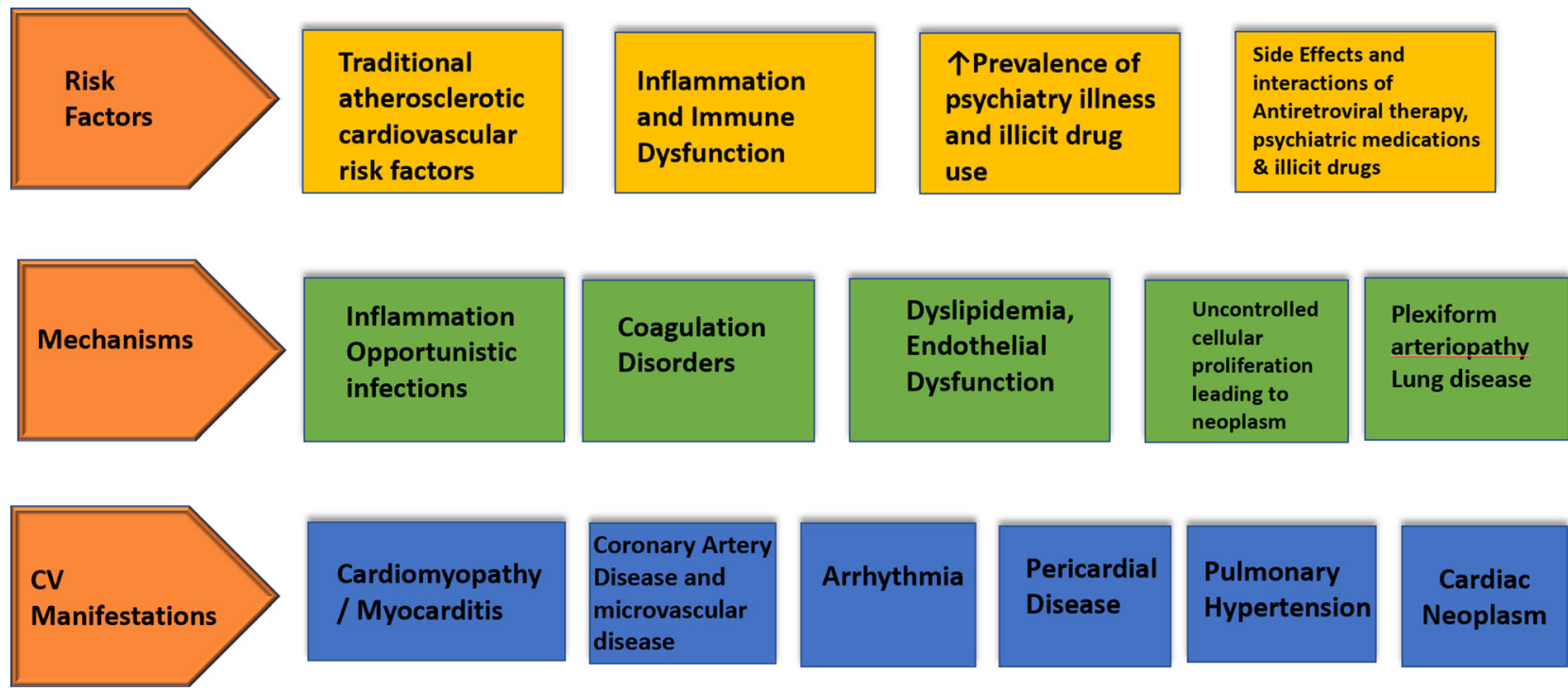

Figure 1. Complex pathophysiology of cardiac manifestations of HIV.

of HIV-related heart disease. Echocardiography remains the first imaging modality to assess myocardial function in patients suspected with heart failure from any cause. Echocardiography serves as a robust and tested modality in assessing various myocardial properties like ventricular function, valvular assessment, and pericardial disease. Echocardiography is the screening test for assessing pulmonary hypertension which is frequently found in patients with HIV. ${ }^{16}$ The utilization of global longitudinal strain assessed by echocardiography in patients with HIV in detecting early systolic dysfunction has detected a correlation between CD4 T-cell count and global longitudinal strain. ${ }^{17,18}$ Stress echocardiography (SE) an established modality in assessing CAD has been well studied in HIV individuals with risk of CAD and effectively stratifies patients into a low- and high-risk category. ${ }^{19,20}$ The presence of ischemia and scar detected by echocardiography serve as independent predictors of CVD in patients with HIV. ${ }^{20}$

Myocardial perfusion imaging (MPI) with singlephoton emission computerized tomography (SPECT) and positron emission tomography (PET) has high sensitivity and specificity in diagnosing CAD in the HIV cohorts. ${ }^{21,22}$ SPECT, which is more commonly available in comparison to PET, is one of the initial tests for evaluating HIV patients with symptoms suggestive of CAD. PET allows evaluation of myocardial perfusion, assessment of quantitative myocardial blood flow (MBF), and coronary flow reserve (CFR). Both PET and SPECT aid in understanding the mechanisms of cardiomyopathy by assessing viability, cardiac stunning, and the presence of scar in patients with HIV which provide valuable insights for definite management. Multi Gated Blood Pool Scan(MUGA), another nuclear imaging modality is the gold standard for getting an accurate estimate of ventricular function. ${ }^{23}$

Multidetector computed tomography (MDCT) is establishing itself as a reliable imaging modality that can accurately identify plaque burden, coronary artery anomalies, and the patency of coronary artery bypass grafts. ${ }^{24,25}$ MDCT has evolved as an adjunct to coronary catheterization in the assessment of patients with intermediate risk of CAD and serve a gatekeeper in ensuring appropriate triage of patients for catheterization. ${ }^{26}$ Measurement of coronary artery calcium (CAC) has proven to correlate well with predicting future cardiac events in the general population. ${ }^{27,28}$ In the Multicenter AIDS cohort study (MACS), MDCT performed on patients with HIV showed a higher incidence of noncalcified plaque with a higher burden observed in patients with higher viremia compared to suppressed viremia. ${ }^{29,30}$

Cardiac magnetic resonance (CMR) can measure ventricular volume, ejection fraction, assess ischemia by evaluating regional wall motion abnormalities, diagnose myocarditis using T2-weighted, early T1-weighted, and delayed gadolinium-enhanced imaging to evaluate infiltrative disease and assessment of myocardial viability in both general and HIV population. ${ }^{31}$ CMR is the gold standard for assessing right ventricular function and a well-validated modality to study pericardial disease and myocardial malignancy. ${ }^{32}$

Like the general population, cardiac catheterization remains the gold standard for the diagnosis and 


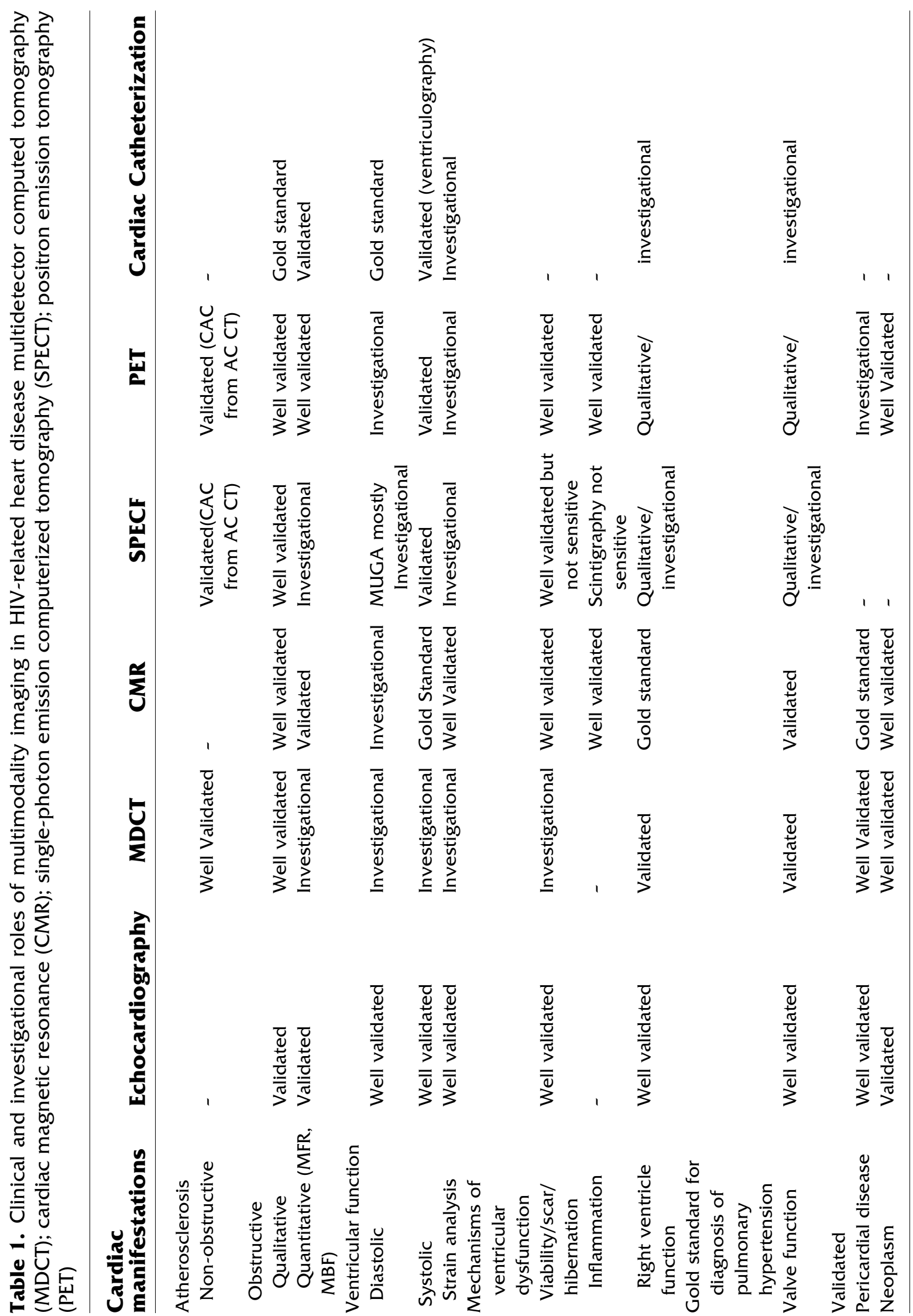


management of obstructive CAD in HIV patients. Right heart catheterization (RHC) remains the gold standard for the diagnosis of pulmonary hypertension. Technological advances in non-invasive cross-sectional imaging modalities like the MDCT, magnetic resonance angiography have shifted the dependence from cardiac catheterization in the assessment of CAD, inflammatory disease of great vessels like aortitis and study of valvular disease.

In conclusion, as patients with HIV are living longer, the prevalence of developing chronic disease with predominant cardiovascular manifestations is growing. The need for better diagnostic and therapeutic interventions for cardiovascular manifestations using multimodality imaging will be the next frontier. Clinicians should be astute in identifying risk factors for cardiovascular manifestations and familiarize themselves with appropriate screening using various imaging modalities and aggressive management of risk factors in HIV cohorts.

\section{Disclosures}

Dr. Bajaj was supported by American College of Cardiology Presidential Career Development Award, Walter B. Frommeyer Jr. Fellowship in Investigative Medicine, and National Center for Advancing Translational Research of the National Institutes of Health under award number UL1TR001417. Drs. Aryal, VonMering and Ahmed no relevant discourse to declare for this manuscript.

\section{References}

1. Mondal P, Aljizeeri A, Small G, Malhotra S, Harikrishnan P, Affandi JS, Buechel RB, Dwivedi G, Al-Mallahc MH, Jain D. Coronary artery disease in patients with human immunodeficiency virus infection. J Nucl Cardiol 2014;7:515-25.

2. Lohse N, Obel N. Update of survival for Persons With HIV infection in Denmark. Ann Intern Med 2016;165:749-50.

3. Prendergast BD. HIV and cardiovascular medicine. Heart 2003;89:793-800.

4. Farahani M, Mulinder H, Farahani A, Marlink R. Prevalence and distribution of non-AIDS causes of death among HIV-infected individuals receiving antiretroviral therapy: a systematic review and meta-analysis. Int J STD AIDS 2017;28:636-50.

5. Feinstein MJ, Bahiru E, Achenbach C, et al. Patterns of cardiovascular mortality for HIV-infected adults in the United States: 1999 to 2013. Am J Cardiol 2016;117:214-20.

6. Boccara F, Mary-Krause M, Teiger E, et al. Acute coronary syndrome in human immunodeficiency virus-infected patients: characteristics and 1 year prognosis. Eur Heart J 2011;32:41-50.

7. Mdodo R, Frazier EL, Dube SR, et al. Cigarette smoking prevalence among adults with HIV compared with the general adult population in the United States: cross-sectional surveys. Ann Intern Med 2015;162:335-44.

8. Triant VA, Lee H, Hadigan C, Grinspoon SK. Increased acute myocardial infarction rates and cardiovascular risk factors among patients with human immunodeficiency virus disease. J Clin Endocrinol Metab 2007;92:2506-12.

9. Zanni MV, Grinspoon SK. HIV-specific immune dysregulation and atherosclerosis. Curr HIV/AIDS Rep 2012;9:200-5.

10. Lo J, Plutzky J. The biology of atherosclerosis: General paradigms and distinct pathogenic mechanisms among HIV-infected patients. J Infect Dis 2012;205:S368-74.

11. Jarrett H, Barnett C. HIV-associated pulmonary hypertension. Curr Opin HIV AIDS 2017;12:566-71.

12. Nedelcovych MT, Manning AA, Semenova S, Gamaldo C, Haughey NJ, Slusher BS. The psychiatric impact of HIV. ACS Chem Neurosci 2017;8:1432-4.

13. Kovari H, Calmy A, Doco-Lecompte T, et al. Antiretroviral drugs associated with subclinical coronary artery disease in the swiss human immunodeficiency virus cohort study. Clin Infect Dis 2020;70:884-9.

14. Bozkurt B. Cardiovascular toxicity with highly active antiretroviral therapy: review of clinical studies. Cardiovasc Toxicol 2004;4:243-60.

15. Lababidi MH, Alhawasli H, Iroegbu N. Kaposi sarcoma can also involve the heart. J Community Hosp Intern Med Perspect 2015;5:29054-29054.

16. Almodovar S, Hsue PY, Morelli J, Huang L, Flores SC, Lung HIVS. Pathogenesis of HIV-associated pulmonary hypertension: potential role of HIV-1 Nef. Proc Am Thorac Soc 2011;8:308-12.

17. Nesbitt GC, Mankad S, Oh JK. Strain imaging in echocardiography: methods and clinical applications. Int J Cardiovasc Imaging 2009;25:9-22

18. Cetin S, Gündüz A, Şabablı Çetin A, et al. Evaluation of subtle left ventricular systolic dysfunction by longitudinal systolic strain in patients with human immunodeficiency virus. Acta Cardiol Sin 2018;34:321-7.

19. Bangalore S, Yao SS, Chaudhry FA. Role of right ventricular wall motion abnormalities in risk stratification and prognosis of patients referred for stress echocardiography. J Am Coll Cardiol 2007;50:1981-9.

20. Wever Pinzon O, Silva Enciso J, Romero J, et al. Risk stratification and prognosis of human immunodeficiency virus-infected patients with known or suspected coronary artery disease referred for stress echocardiography. Circ Cardiovasc Imaging 2011;4:363-70.

21. Catzin-Kuhlmann A, Orea-Tejeda A, Castillo-Martínez L, et al. Human immunodeficiency virus-infected subjects have no altered myocardial perfusion. Int J Cardiol 2007;122:90-2.

22. Mariano-Goulart D, Jacquet JM, Molinari N, et al. Should HIVinfected patients be screened for silent myocardial ischaemia using gated myocardial perfusion SPECT? Eur J Nucl Med Mol Imaging 2013;40:271-9.

23. Yang S-N, Sun S-S, Zhang G, et al. Left ventricular ejection fraction estimation using mutual information on technetium-99m multiple-gated SPECT scans. Biomed Eng Online 2015;14:119119.

24. Donnelly PM, Higginson JDS, Hanley PD. Multidetector CT coronary angiography: have we found the holy grail of non-invasive coronary imaging? Heart 2005;91:1385-8.

25. Achenbach S, Giesler T, Ropers D, et al. Detection of coronary artery stenoses by contrast-enhanced, retrospectively electrocardiographically-gated, multislice spiral computed tomography. Circulation 2001;103:2535-8.

26. Kopp AF, Küttner A, Trabold T, Heuschmid M, Schröder S, Claussen CD. MDCT: cardiology indications. Eur Radiol 2003; 13:M102-15.

27. Detrano R, Guerci AD, Carr JJ, et al. Coronary calcium as a predictor of coronary events in four racial or ethnic groups. N Engl J Med 2008;358:1336-45. 
28. Polonsky TS, McClelland RL, Jorgensen NW, et al. Coronary artery calcium score and risk classification for coronary heart disease prediction. Jama 2010;303:1610-6.

29. Kingsley LA, Cuervo-Rojas J, Muñoz A, et al. Subclinical coronary atherosclerosis, HIV infection and antiretroviral therapy: Multicenter AIDS Cohort Study. Aids 2008;22:1589-99.

30. Ryan T, Affandi JS, Gahungu N, Dwivedi G. Noninvasive cardiovascular imaging: Emergence of a powerful tool for early identification of cardiovascular risk in people living with HIV. Can J Cardiol 2019;35:260-9.
31. Friedrich MG, Sechtem U, Schulz-Menger J, et al. Cardiovascular magnetic resonance in myocarditis: A JACC White Paper. J Am Coll Cardiol 2009;53:1475-87.

32. Li X, Chen Y, Liu J, et al. Cardiac magnetic resonance imaging of primary cardiac tumors. Quant Imaging Med Surg 2020;10:294313.

Publisher's Note Springer Nature remains neutral with regard to jurisdictional claims in published maps and institutional affiliations. 